\title{
Modern principles of strategic planning for the central part development in Tambov
}

\author{
Yaroslav Savinov ${ }^{1}$, Victor Ledenev ${ }^{2}$, Ali Yahya Nasser AL-Bukhaiti ${ }^{*}$, Yaya Keita $^{2}$, Olga \\ Umnova $^{2}$ \\ ${ }^{1}$ LLC JV Mosstroy, Tambov district, 392551, Tambov Region, Russia \\ ${ }^{2}$ Tambov State Technical University, 392000, Tambov, Russia
}

\begin{abstract}
Unfortunately, modern mass construction does not take into account all the influencing factors on buildings, however, considerable experience has been accumulated over the past decades of design, construction and operation. A method of zoning the central part of the city, taking into account the peculiarities of the engineering-geological and hydrogeological structure of the territory, the terrain, the nature of the development and the technical condition of buildings, has been proposed. Significant areas of dilapidated housing have been marked. The concept of strategic planning and the rules for the development of promising areas in the central part of Tambov, taking into account the peculiarities of its structure, have been developed. These recommendations are universal and can be used in the construction of residential quarters in the cities in the European part of Russia and Europe.
\end{abstract}

\section{Introduction}

The city of Tambov emerged as a wooden fortress at the mouth of the river Studenets in the river Tsna. It is located in the central European part of Russia, and is built on the left side of the Tsna River valley, in this sense it is a typical European city, since people have been building the cities on the banks of large rivers for a long time. Consequently, the geomorphology of the foundations' soils in various coastal cities is largely similar. The central historical part of Tambov, which was built up pointwise, without a single strategic plan [1], therefore, modern buildings are adjacent to the buildings over 100 years old, is considered below (refer with Fig. 1). This paper proposes the recommendations for the development of promising quarters, taking into account the existing experience and geological data $[2,3]$. Initially, 10 small rivers and streams with their feeding basins and valley complexes flowed on the territory of the city, now only a third of them have been partially preserved, their function to some extent was taken over by the city storm sewage system. All this has led to a significant seasonal rise in groundwater and upgrade stream water $[1,2,6,7]$, while the rivers and streams are not only drainage value, but also give an aesthetic flavor to the city with the appropriate design.

Figures $1 \mathrm{a}, \mathrm{b}$ show a fragment of the central part of the city within the area of $1,8 \mathrm{~km}^{2}$. The northwestern part of the fragment (marked with an oblique stroke) with an area of 0,55

\footnotetext{
*Corresponding author: al_bukhaiti@mail.ru
} 
$\mathrm{km}^{2}$, which is $30.6 \%$ of the area under consideration, is a promising dilapidated building, for which the authors have developed a concept of integrated development. The technical condition of the capital buildings in the investigated area is divided into three categories according to the degree of damage to the facades. The analysis showed that the buildings with damages on the facades are built of mansory and have shallow strip foundations, up to 2 meters deep. Their age is over 70 years old.

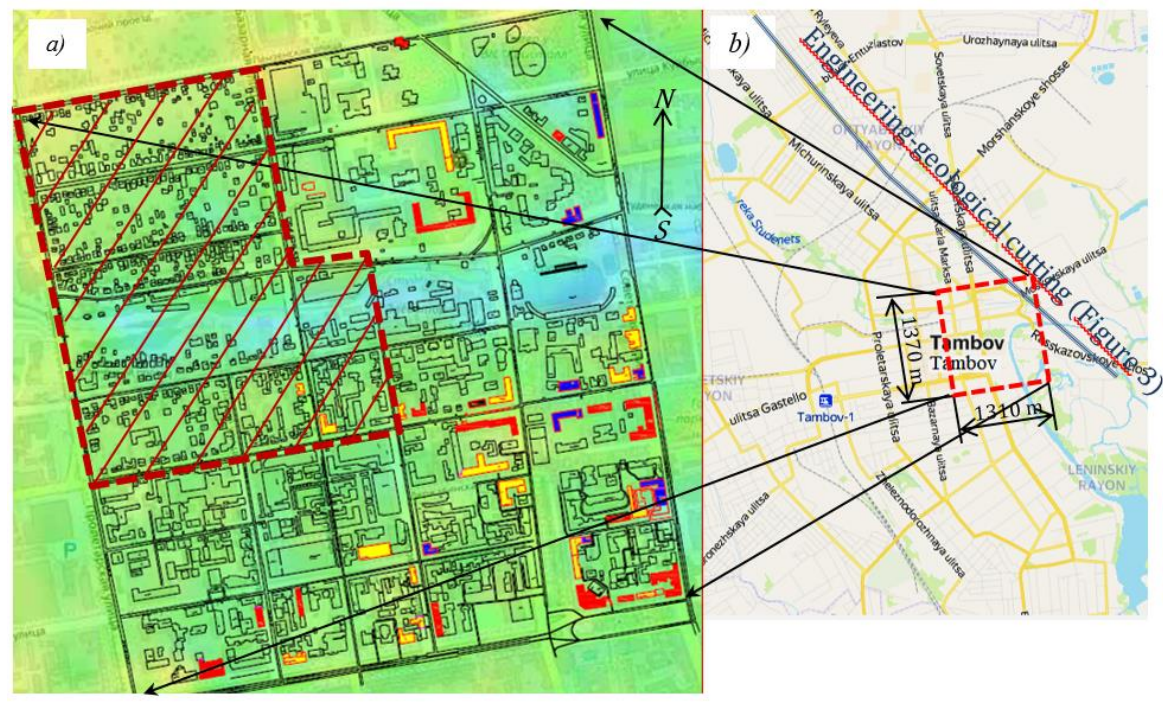

Fig. 1. The central part of Tambov: a) residential and public buildings with varying degrees of damage to the front walls; $b$ ) Tambov indicating the location of the investigated part.

- buildings with cracks, opening width $>5 \mathrm{~mm}$;
- buildings with cracks, opening width $3-5 \mathrm{~mm}$;
- buildings with cracks with an opening width of $<3 \mathrm{~mm}$;
- neighborhoods with dilapidated housing for demolition.

The causes of cracks on the buildings' facades have already been considered in detail by the authors [9], briefly the main ones can be mentioned:

- High variability and low rates of mechanical properties of the foundation soils [2].

- Insufficient buildings rigidity: a brick box made of load-bearing walls is weakly connected to wooden partitions and ceilings.

- Impact of vibrations from urban transport of water-saturated foundation soils.

- Lack of repair and restoration work and measures for drainage and water disposal of territories.

The area under consideration with the dimensions $1370 \times 1310 \mathrm{~m}$ is located on the second bottom terrace of the Tsna River valley, and in the northwest, it slightly enters the third bottom. It is characterized by the features noted below:

1. Relief is flat, has a general smooth slope from the north-west to the south-east with absolute elevations from 137 to $128 \mathrm{~m}$ with local elevations of individual sections up to 139 $\mathrm{m}$ and there are also small lowlands up to $124 \mathrm{~m}$ (refer with Fig. 2, b). The main relief feature of the area under consideration is the channel of the Studenets River with its small valley, which is a natural drainage for the central part of the city. It lowers groundwater table by 3$4 \mathrm{~m}$. The marks of the river valley Studenets decrease from $124 \mathrm{~m}$ to $120 \mathrm{~m}$. The adjacent 
territories are the elements of its small valley and slope towards its channel. The nature of the terrain and the location of large buildings affects the direction and upgrade stream water movement speed, as well as the places of its natural accumulation. For example, the buildings located with a "well" or across the natural slope experience hydrostatic pressure from the side of the upgrade stream water movement, along their foundations they accumulate moisture, and during the period of snow melting, their basements are often flooded. Figure $2 b$ shows the direction of the upgrade stream water movement, depending on the terrain, and several low-lying areas to the north of the river Studenets on which water is accumulated.

2. Ground water repeats the terrain and lies in the aquifer of aluvial sands at a depth of 3-5 m (refer with Fig. 2, a). They are moving towards the Tsna river from the north-west to the south-east, and in the area of the floodplain of the Studenets river - in the direction of its channel. For groundwater table seasonal fluctuations in burial depth are typical. In spring it rises by 1-2 m, and in winter it decreases within the same limits. During the period of snow melting, upgrade stream water appears, which lies at a depth of $0 \ldots 2 \mathrm{~m}$ on the aquiclude of alluvial loams and moves according to the rules of the relief to lower elevations.
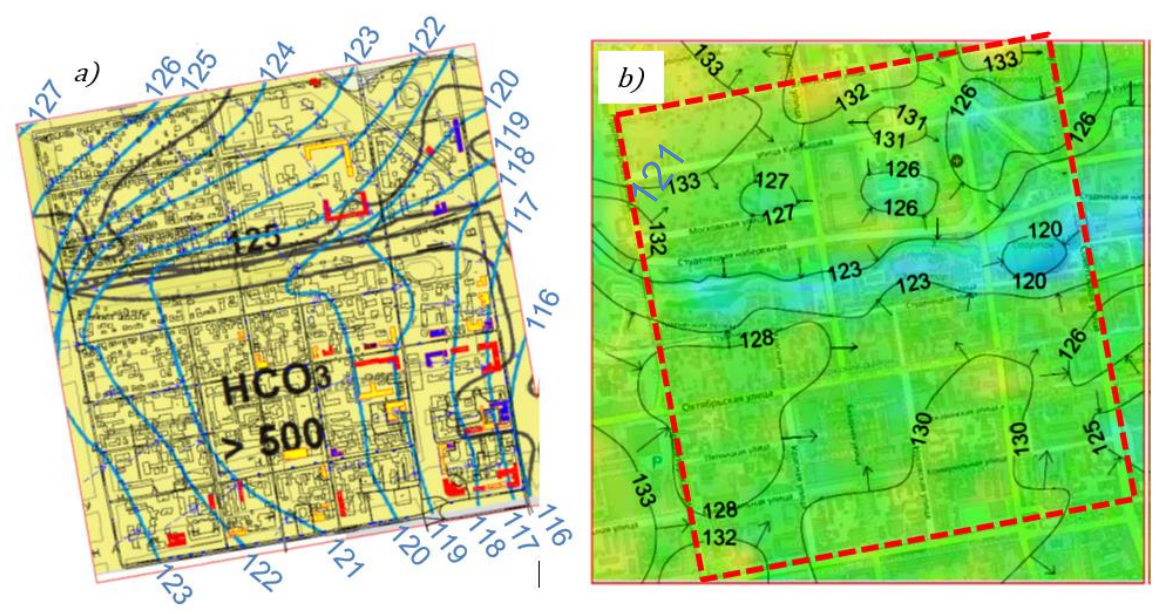

Fig. 2. Ground waters and upgrade stream water: a) elevation marks of hydroisohypsum and chemical composition of subterrain waters; $b$ ) the direction of the drift of the upgrade stream water in accordance with the terrain and its height marks.

The city center is characterized by a large $\left(>500 \mathrm{mg} / \mathrm{dm}^{3}\right)$ content of low-corrosive bicarbonate anion $\mathrm{HCO}_{3}$ and a small content of the sufat anion, which is aggressive to concrete $\mathrm{SO}_{4}\left(<500 \mathrm{mg} / \mathrm{dm}^{3}\right)$. The appearance of these anions is caused by the high hardness of the groundwater and the presence of buried or functioning outdoor cesspools, since there was a private sector everywhere previously. The groundwater of this part of the city can be considered slightly aggressive.

3. Based on the geological data of individual construction sites, we have built [4] an engineering-geological section of Tambov, stretching from the north-west to the south-east along Michurinskaya street to Naberezhnaya street, and illustrates the structure of the stratigraphic elements that make up the left side of the Tsna river valley (refer with Fig. 3). The section shows a horizontally compressed diagram of the structure of soil layers in the proportions of the vertical scale to the horizontal scale: $h / l=1 / 50$. The first thing that catches your eye is the high variability and complexity of the structure of the upper geological layers to a depth of 6-8 $\mathrm{m}$ and a more stable structure of the underlying layers. The top layer is almost everywhere man-triggered (technogenic) deposits, not suitable as the foundation base, 1.5-3 $\mathrm{m}$ thick, and in some places they reach up to $8 \mathrm{~m}$. 
The study area on the northern border with the floodplain of the Studenets River has a significant set off up to $8 \mathrm{~m}$ high. The consistency of clay soils here varies from hard and semi-hard to tough-plastic. The terrace is made of Upper Quaternary alluvium $a(2 t) I I I$, which is an interbedded loess-like loam, clay and sandy loam with a thickness of $2 \ldots 5 \mathrm{~m}$.

The lower horizon of alluvial deposits is formed by sands more than $8 \mathrm{~m}$ thick. These rocks are underlain by the sands of the Cretaceous system $K$, from above they are often overlain by dealluvial loess-like loams and clays $L d I I I$ with loam lenses of the I-th type, and sometimes of the II-th type of soil conditions for subsidence*. The scheme of engineeringgeological zoning compiled by the authors according to the deformative properties of soils (refer with Fig. 4) [6] shows that the southern part of the area under consideration has low values of the deformation modulus due to the nearby ground waters. The central and northern parts of the region have higher deformative characteristics, here the Studenets river drains well this part of the city, therefore, the areas of subsidence loess-like loams of the first type have been preserved. The values of the deformation modulus are highlighted in colors, the greater the slope of the terrain and the higher the absolute elevations of the relief, the higher the deformation modulus. The lowest values are in the floodplain of the Studenets river, and high on the well-drained slopes of the valley of this river and in the elevated areas. In the northern part of the site and on the southern bank of the Studenets river there are areas with subsidence properties of the I-th type.

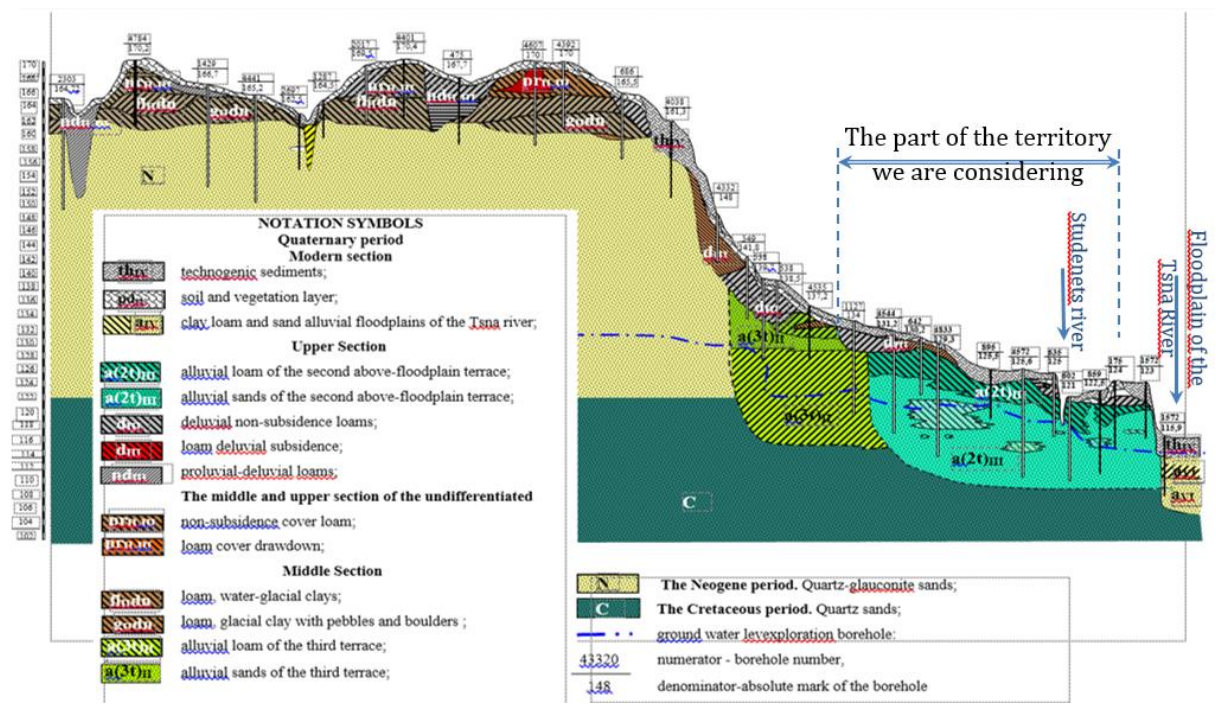

Fig. 3. Engineering-geological section 1-1 along the Michurinskaya street. Horizontal scale 1: 50000, vertical scale 1: 1000 .

Having imposed the house with a substantial degree of damage on the geological diagram, it is possible to notice the following regularities: most deformed houses are located in the territory of low values of the deformation modulus, as well as in the territory of subsiding soils in the southwest of the area under consideration. On the dangerous site of subsiding deluvial loams, located on the southern bank of the Studenets river, there are few deformed buildings, since non-capital residential buildings have been built here. 


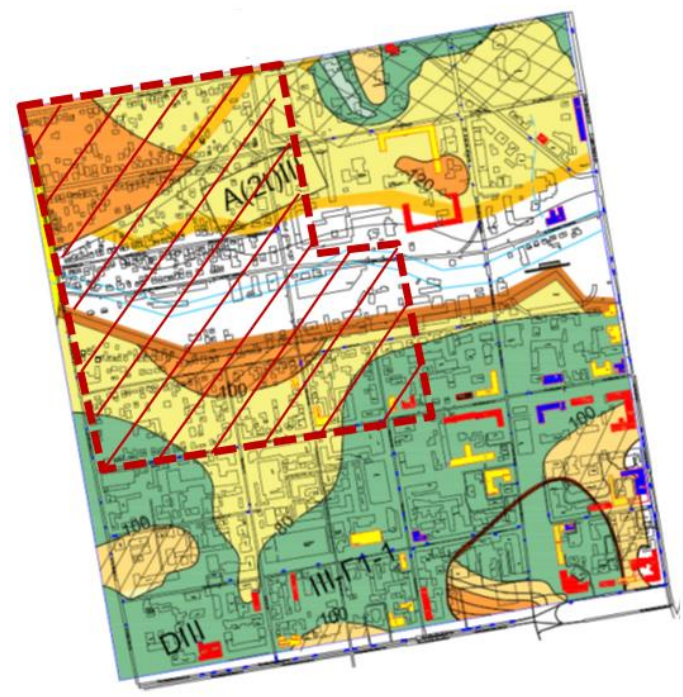

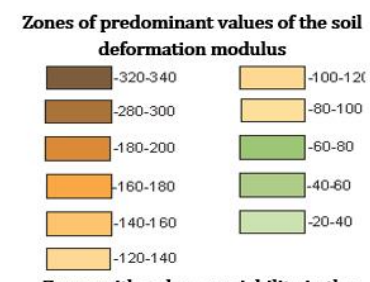

Zones with a sharp variability in the deformative characteristics of soils s. $-Q>4,5$ MI $-Q>3$ T. $-Q>2$ Zones of development of engineeringgeological and natural-geological processes $\equiv \equiv$ Waterlogging

Modern ravine formation Dubsidence soils

Fig. 4. Scheme of engineering-geological zoning.

\section{Recommendations}

From the point of view of engineering geology, the following areas for which special recommendations are given below, can be distinguished (refer with Fig. 5). Low places where upper ground water is accumulated often have frost heaving. Ancient buildings are very sensitive to heaving soils. In such areas, it is necessary to take measures for drainage and lowering groundwater table. Understanding the direction of movement and the rate of groundwater filtration is necessary to prevent the accumulation of groundwater at the foundations, and the formation of water pockets. Therefore, it is necessary to orient buildings elongated in the plan with long facades along the direction of the relief slopes. Closed well courtyards are poorly ventilated, poorly insolated, atmospheric waters are poorly drained, it is desirable to open them from the side of the slope (refer with Fig. 5, b). Quarters located in the lowlands should be equipped with additional storm sewer wells, with a branch to the city network.

Let us cite the main provisions of our proposed development concept for a promising area (refer with Fig. 5, b), taking into account the works [4, 5, 7, 8, 10]:

- The valley of the Studenets river is not being built up, on the contrary, it becomes a quiet park zone, which enters the inner parts of the courtyards (park-yards "without cars"), uniting them together. At the same time, it is recommended to clear this territory and arrange here a park recreation area with green spaces that strengthen the coastal slopes.

- Park-yards "without cars" are formed not by the closed yards by "wells", but by the open ones. Moreover, the open parts of the houses are turned towards the terrain slope (towards Studenets river).

- Houses are equipped with basement-garages with an access to the outer street side.

- The houses forming the quarters have separate exits from the entrances to: underground basement-garages, to the "courtyard without cars"; to the outer street part, where shops are located, car exits to the roadway.

- It is recommended to build light residential buildings with a rigid monolithic reinforced concrete frame with a free studio layout with effective external gas silicate insulation with multicolor brick lining. 

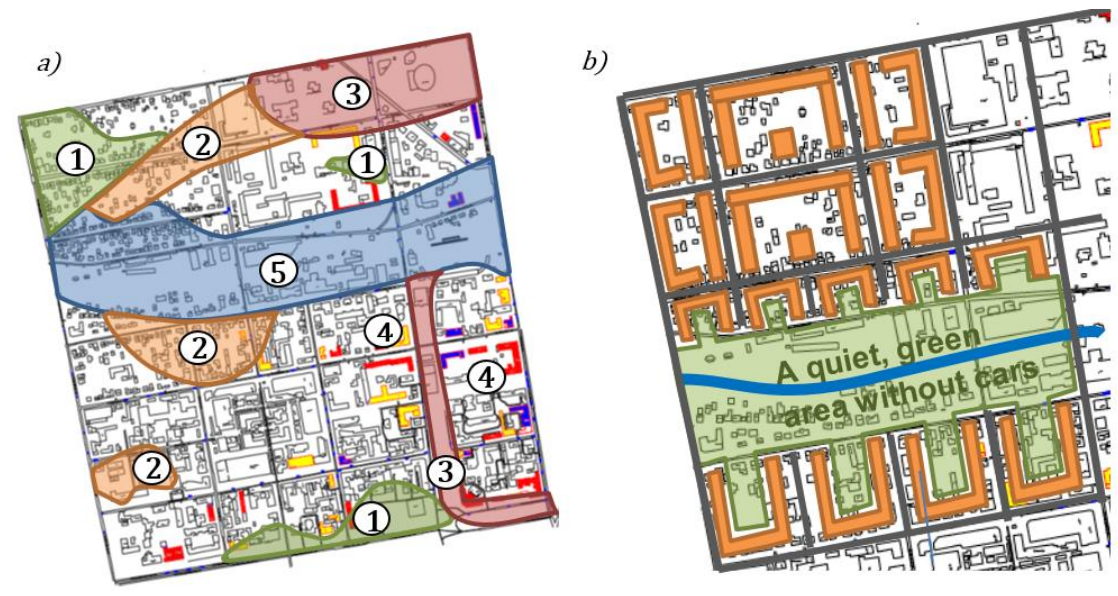

Fig 5. Territorial zoning of the central part of Tambov: a) by the type of soil conditions; b) the idea of building a promising area, from the point of view of hydrogeology.

\section{Legend and recommendations for Figure 5 a:}

- 1st type "Favorable geological conditions". Optimal design and technological, sanitary aesthetic decisions are made taking into account the architectural expressiveness, modern design standards, cast-in-situ strips are not required.

- 2nd type "Subsidence soils". The foundations here can also be tape, but the measures are needed to prevent uneven subsidence: waterproofing trays under the water supply and drainage systems, cast-in-situ strips at the floor level. Territory planning, taking into account the diversion of upper ground water from the facades of buildings.

- 3rd type "High variability of deformative properties of soils" up to 3 times with the presence of collapsing soils. This type of soil is the most problematic; it requires a combination of measures for subsidence soils in combination with an increase in the buildings supporting structures rigidity in general. For example, a monolithic reinforced concrete foundation, a monolithic reinforced concrete frame, cast-in-situ strips at the floor level of all floors.

$\square$ - 4th type "Loose soils". Soils with a low modulus of deformation, groundwater is located close. Buildings require increased rigidity combined with increased base width for shallow foundations.

- 5th type "Floodplain of the Studenets river". Only pile foundations are applicable here. Measures to protect against suffusion of soils of the aquifer are required. Reinforced vertical and horizontal waterproofing of foundations is recommended.

\section{Summary}

1. The modern general strategy for the development of the central and historical part of Tambov can be applied to architecturally expressive buildings up to 5 floors high, which is associated with the currently selected provincial style of the city. Such buildings are characterized by the shallow strip foundations up to $2.5 \mathrm{~m}$. The design depth of the compressible strata of such buildings varies within $4 \ldots 5 \mathrm{~m}$. Therefore, groundwater here can manifest itself only during the flood period.

2. The survey showed that the overwhelming majority of the deformed buildings are on the type 4 soil conditions (Fig. 5, a) with a low modulus of deformation and a high 
groundwater table. As a rule, these buildings are older than 40 years old, having shallow brick foundations that do not provide the required rigidity to the building as a whole.

3. Recommendations are given for a modern strategy for the quarters' design.

4. Infill development entails a lot of problems. New promising areas need to be built up in an all-round manner, taking into account the discharge of groundwater (Fig. 5, b) and all factors influencing reliability.

\section{References}

1. S.V. Belov, Yu.I. Popov, A.G. Yurin, Tambov is a city on the Tsna river. Problems of water disposal in the history of the formation and development of urban territory, MBU "Spetsdorservice", Tambov, Moscow, SPb, Baku, Vein, Hamburg, Stockholm, publishing house of INC "Nobilietika", 2017.

2. A.A. Gorelov, Yu.K. Shchukin, TAMBOV Guidebook (Central part) (Tambov, state type "Proletarian Light", 2000).

3. A.B. Danish, V.V. Ledenev, Ya. V. Savinov, A. Ya. Al-Buheiti, Building Mechanics and Structures. 2 (21) (2019) 98 - 108.

4. V.V. Ledenev, Deformation and destruction of foundations, foundations, building materials and structures (theory, experiment), monograph (Publishing Center of the Federal State Budgetary Educational Institution of Higher Education "TSTU", 2018).

5. V.I. Osipov, V.N. Burova, E.A. Karfidova, Foundations and soil mechanics 6, 32-36 (2016).

6. Report of the laboratory of PSIIER Gosstroy of the RSFSR SPO "Stroyiziskaniya", Tambov, 1988.

7. Ya.V. Savinov, I.L. Vasiliev, A.L. Tumanyan, Features of engineering-geological zoning of the territory of Tambov, Proceedings of TSTU: Scientific collection of the works of young scientists and students (Publishing house of TSTU, Tambov) 4, 124 (1999).

8. Ya.V. Savinov, The main damage to the bearing elements of buildings and proposals for their accounting when calculating the example of the city of Tambov, PhD Thesis, Voronezh, 2003.

9. Ya.V. Savinov, V.V. Ledenev, Causes of damage to buildings in Tambov and their prevention, Problems of construction, engineering support and ecology of cities. Materials of the II International Scientific and Technical Conference, Penza, 2000.

10. V.A. Ilyicheva, R.A. Mangusheva, Reference book of geotechnics. Foundations, foundations and underground structures (Moscow, ASV, 2016). 